\title{
Medicine, ethics and religion: rational or irrational?
}

\author{
Robert D Orr, and Leigh B Genesen Loma Linda University Medical Center, Loma Linda, California and \\ Lovelace Hospital, Albuquerque, New Mexico, USA, respectively
}

\begin{abstract}
Savulescu maintains that our paper, which encourages clinicians to honour requests for "inappropriate treatment" is prejudicial to his atheistic beliefs, and therefore wrong. In this paper we clarify and expand on our ideas, and respond to his assertion that medicine, ethics and atheism are objective, rational and true, while religion is irrational and false.

(Fournal of Medical Ethics 1998;24:385-387)
\end{abstract}

Keywords: Religion; ethics; rational; irrational; futility; social justice

In a critique of our proposal that clinicians should give serious consideration to requests for "inappropriate" treatment when those requests are based on religious beliefs, ${ }^{1}$ Savulescu overstates our position, conflates the terms "inappropriate", "futile", "harmful", and "cost-ineffective", and goes on to claim both objectivist and subjectivist reasons why our position is prejudicial and wrong. ${ }^{2} \mathrm{He}$ presents three pairs of hypothetical cases and presumes to know how we would assess each one. He concludes that religion is false and irrational, while both atheism and ethics are true and rational. His reading of our position is confused. We appreciate the opportunity to clarify and expand upon our position, because it is assumptions like Savulescu's that religious beliefs are irrational and false and therefore irrelevant which prompted our article in the first place.

There is not sufficient space here, nor is this the proper forum, to present an apologetic for theism, but we would like to defend its rationality. We agree with Culver and Gert that it is more basic and more important to define irrationality than rationality, and we further agree with their definition that "actions, beliefs, and desires [are] irrational only when there is likely to be nearly universal agreement that they are indeed irrational" and with their assertion what is not irrational is rational, either rationally required or rationally allowed. ${ }^{3}$ While plurality may not be sufficient to convince Savulescu of the truth of theism, it is clear that the vast majority of people in our society do believe in God, so that theism, by definition, in not irrational.

In our paper, we recognised that physicians sometimes decline to provide treatments demanded by patients "based on medical futility, medical standards, patient suffering, lack of net benefit to the patient, or cost". "In addition we stated that "[i]n most situations, physician refusal to provide 'medically inappropriate' treatment is professionally sound". ${ }^{5}$ We carefully defined our use of "inappropriate" in quantitative and qualitative terms. ${ }^{6}$ We presented four actual cases where "inappropriate" treatment was requested because of religious beliefs. We then discussed the theological assumptions underlying those requests, and presented some theological arguments which might counterbalance those requests. We concluded that such requests should be given serious consideration rather than discounted as mystical or irrational. While we did go on to say that persistent requests based on religious beliefs should most often be honoured, we affirmed that such claims are not absolute and that physicians should occasionally refuse to provide such treatments. In light of Savulescu's misreading of our conclusions, we regret that we did not attempt to give criteria for those situations when this would be justified, especially since our assessment of his hypothetical cases so nearly matches his own.

He offers case 1a as an example of a treatment request based on cultural tradition and case $1 \mathrm{~b}$ as a similar request based on personal preference, claiming we would provide the treatment for $1 \mathrm{a}$ but not for $1 \mathrm{~b}$, thereby implying that cultural tradition and religious beliefs are synonymous. One of us has written on the importance of respecting cultural beliefs in the practice of medicine ${ }^{7}$ and also in clinical ethics. ${ }^{8}$ However, a patient's culture encompasses much more than religion. While we would strive to understand the basis for all 
requests for treatment, and would attempt to honour both cultural and religious beliefs when this is possible, we would not provide the harmful procedure requested in either $1 \mathrm{a}$ or $1 \mathrm{~b}$.

Cases $2 a$ and $2 b$ are quite different in that the girl in $2 \mathrm{a}$ is dead by neurological criteria, while the man in $2 b$ is in a persistent (and presumed permanent) vegetative state. We entirely agree with his assessment that the demand for continued treatment of the girl in 2a should not be honoured because she is dead. Continued treatment of a corpse is not only futile, we believe it is immoral. We also agree that the man in $2 b$ should be given basic care based on his values. Our assessment has nothing to do with the religious beliefs of the girl's family or the man's lack of belief in an afterlife.

Similarly, we believe that the requests in $3 \mathrm{a}$ and $3 \mathrm{~b}$ for very expensive treatment with a one in a million chance of being effective should be denied based on social justice, regardless of whether the request is based on religious beliefs or personal preference. But we would emphasise that the request in $3 \mathrm{a}$ should not be quickly dismissed merely because it is based on a belief in miracles.

\section{Short term treatment}

We failed in our article to present our recommendations in the four cases reported or to give criteria we might use to assess religiously based requests for treatment. In fact we did recommend continued use of "inappropriate" treatment in case 1 (a child imminently dying of a malignancy whose father said "Only Allah can take a life"), case 2 (a young man dying of a brain tumour whose parents insist on treatment because "We are waiting for God to perform a miracle"), and in case 3 (a child in multi-organ system failure after surgery whose mother insists "God told me he will survive"), but we recommended against continued treatment in case 4 (an elderly woman with an inoperable dissecting aortic aneurysm whose sister insists "She's not ready to die"). The first three cases involved relatively short term treatment in that the patients were clearly and imminently dying, and none of them was experiencing unrelievable suffering. While the requested treatments were quite expensive, the anticipated short duration made claims of social justice less persuasive. We recommended against continued treatment in the fourth case because the religious belief underlying the request was that of a relative and it was not shared by the patient.

Thus we agree with Savulescu that patient suffering, allocation of scarce resources, and cost must be considered in all treatment decisions. But we maintain that religious beliefs must be added罩 to the equation, not considered irrelevant and dismissed without consideration.

Savulescu claims objectivist reasons for his $\overrightarrow{\vec{F}}$ criticism of our position, but includes in hiş objectivist assessment "values of the physica름. circumstances", carrying on "worthwhile relation- $-\frac{\bar{\sigma}}{\bar{\sigma}}$ ships", and achieving "worthwhile goals". Thesę all sound like subjective assessments to us. Whates may be of value or worthwhile to one person, may $\overrightarrow{0}$ be deemed without value to another.

While also granting credence to subjectivistw reasons, he states "there is no reason to give pref erence to religious values over non-religiousp values". Our position was based heavily or Wreen's cogent arguments outlining why religiousos beliefs are special in regard to treatment refusal. $\omega_{\infty}^{\omega}$ We summarised his argument in three paragraphs $^{10}$ and expanded his thesis to include? requests for "inappropriate" treatments. We would refer readers and Dr Savulescu to Wreen's excellent article for a more thorough treatment of the topic.

We understand Savulescu's point that our position appears to be "morally objectionable dis $\vec{e}$ crimination against atheists". Our primary int was to distinguish requests based on religicio beliefs from those which are selfish, inexplicalyes or whimsical, and to encourage clinicians to con-⿳亠二口犬 sider carefully such requests rather than brushing them off because they are irrational. In response to̊ his criticism, we would define "religion" in broact terms to include any shared world view which $\beta$ informs values and choices, rather than his narrower requirement of theism. By this broader definition, his atheism/materialism would take on the stature of a religion. Thus, if he were to request "inappropriate" treatment in order to pre-3.3. serve every possible moment of life in order tog avoid the personal extinction he anticipates as death, this religious value should be honouredo within the constraints of suffering, cost, and social justice alluded to above. Such special considera-o tion given to religious beliefs would still allow a physician to decline to provide "inappropriate' treatment to a patient who asked for it "just because I want it" or "because I don't want to die until after the Super Bowl".

We are not convinced, as Savulescu appears teo be, that medicine, ethics and atheism are rationa $\bar{D}$ and true, while religion is irrational and false. If this mechanistic view of medicine were correct, it could be practised by algorithm or computer. We are not yet ready to forgo the vital ingredient o clinical judgment, nor to ignore the psychosocia $\mathbb{B}$ and spiritual dimensions of patient care. While Savulescu says that "[e] thics is about what is right 
and wrong, about what we have reason to do...", we find the cases on which we are asked to do ethics consultations are almost always "in the grey area" where reason alone does not help us determine clearly what is the right or wrong thing to do. We view our role as ethics consultants as being to establish the boundaries of what is ethically permissible, not to declare what is the absolute ethically right thing to do.

Robert D Orr, MD, is Director of Clinical Ethics at Loma Linda University Medical Center, Loma Linda, California and Leigh $B$ Genesen, $R N$, is Clinical Ethicist at Lovelace Hospital, Albuquerque, New Mexico, USA.

\section{References}

1 Orr RD, Genesen LB. Requests for "inappropriate" treatment based on religious beliefs. Fournal of Medical Ethics 1997;23:142-7

2 Savulescu. Two worlds apart: religion and ethics. fournal of Medical Ethics 1998; 24:382-4.

3 Culver CM, Gert B. Philosophy in medicine. Oxford: Oxford University Press, 1982:26

4 See reference 1: 142 .

5 See reference $1: 5$.

6 See reference 1: 143

7 Orr RD. Treating patients from other cultures. American Family Physician 1996;53:2004-6

8 Orr RD, Marshall PA, Osborn J. Cross-cultural considerations in clinical ethics consultations. Archives of Family Medicine 1995;4:159-64.

9 Wreen MJ. Autonomy, religious values, and refusal of lifesaving medical treatment. Fournal of Medical Ethics 1991;17:124-30.

10 See reference 1: 145. 